\title{
ILCEA
}

Revue de l'Institut des langues et cultures

d'Europe, Amérique, Afrique, Asie et Australie

$16 \mid 2012$

La culture progressiste à l'époque de la guerre froide

\section{Nulla aesthetica sine ethica. Una aproximación crítica a la historia del arte comprometido contra el franquismo}

Nulla aesthetica sine ethica. A critical approach to the history of engaged art against francoism

Noemi de Haro García

\section{OpenEdition}

Journals

Edición electrónica

URL: http://journals.openedition.org/ilcea/1290

DOI: $10.4000 /$ ilcea. 1290

ISSN: 2101-0609

Editor

UGA Éditions/Université Grenoble Alpes

Edición impresa

ISBN: 978-2-84310-232-5

ISSN: 1639-6073

\section{Referencia electrónica}

Noemi de Haro García, «Nulla aesthetica sine ethica. Una aproximación crítica a la historia del arte comprometido contra el franquismo», ILCEA [En línea], 16 | 2012, Publicado el 04 julio 2012, consultado el 22 marzo 2021. URL: http://journals.openedition.org/ilcea/1290 ; DOI: https://doi.org/ 10.4000/ilcea. 1290

Este documento fue generado automáticamente el 22 marzo 2021.

(c) ILCEA 


\title{
Nulla aesthetica sine ethica. Una aproximación crítica a la historia del arte comprometido contra el franquismo
}

\author{
Nulla aesthetica sine ethica. A critical approach to the history of engaged art \\ against francoism
}

Noemi de Haro García

\section{Historia del arte y política}

1 El libro pionero en estudios culturales sobre España, Spanish Cultural Studies, dedicaba un solo capítulo a la pintura y la escultura del franquismo (Dent, 1995). El arte politizado y los movimientos críticos ocupaban una parte importante de un texto que se interesaba principalmente por la pintura y escultura producidas entre 1960 y 1970 . Tal y como indicaban las editoras, esta publicación colectiva había sido concebida como un libro de consulta que proporcionara una panorámica acerca de tendencias y cuestiones, para animar a los especialistas a realizar trabajos futuros desde el punto de vista de los estudios culturales (Graham y Labanyi, 1995). Habría que entender, entonces, que sus capítulos no sólo reflejaban las grandes líneas de los relatos existentes en ese momento sobre la cultura española en distintas disciplinas, sino que constituían una selección de aquello que se consideraba que podía suscitar el interés de los especialistas en estudios culturales. En efecto, así ha sido en el caso de gran cantidad de los temas apuntados en esta publicación; sin embargo, no ha ocurrido lo mismo en lo que respecta a la pintura y escultura española de las últimas décadas de la dictadura. ¿Por qué?

2 A mi juicio, el escaso interés suscitado por estos objetos y su historia en dicho campo de estudio es un síntoma del tipo de discurso historiográfico que se ha hecho cargo de estos objetos culturales. La historia del arte español que se ocupa de los años 1950, 1960 
y 1970 presenta un relato cerrado y autónomo para explicar el desarrollo artístico de ese periodo. Un tipo de relato que, sin duda, ha dificultado el planteamiento de cuestiones que, como ocurre en el caso de los estudios culturales, abren el análisis de las "obras de arte" a un campo mucho más amplio, que trasciende los límites disciplinares tradicionales. Tal y como han señalado Jesús Carrillo $(2007,2009)$ y Alberto López Cuenca (2004) la historia (académica) del arte español del franquismo se construyó en la pugna entre dos grupos de críticos e historiadores del arte: aquellos que abogaban por un arte comprometido política y socialmente de una parte, y, de la otra, los que rechazaban esta idea y reclamaban la autonomía despolitizada del arte. Entre los primeros se hallaban los componentes del equipo organizador de la exposición española en la Bienal de Venecia de 1976 como eran Valeriano Bozal y Tomás Llorens. Entre los segundos estaban personas vinculadas al entorno del catedrático de la Universidad Complutense Antonio Bonet Correa como Juan Manuel Bonet, Ángel González y Francisco Rivas que declaraban en la exposición 1980 en la galería Juana Mordó de Madrid su propuesta de que el arte español se dirigiera por el camino de la pintura.

El enfrentamiento y la polémica tuvieron su momento álgido en los años 1970 y principios de los 1980 pero no se saldó con la derrota de ninguno de los contendientes. La historiografía reflejaría lo que se podría considerar una negociación entre posiciones elaborada en el molde de una historia del arte tradicional, marcada por los juicios estéticos y la autonomía. A grandes rasgos, el resultado sería un relato vertebrado por la recuperación de la vanguardia en el arte español durante el franquismo donde se reconocían ciertos episodios de politización del arte motivados por la dictadura del país y que, por tanto, habían de extinguirse con el dictador. Dicha historia culminaría con la efectiva y necesaria separación entre arte y política con la llegada de la democracia y la incorporación del país a la dinámica internacional. Un buen ejemplo de ello se encuentra en la obra coordinada por Francisco Calvo Serraller España: medio siglo de arte de vanguardia 1939-1985 donde se proporcionaba además de una extensa cronología de las actividades artísticas del país durante esos años, unos capítulos introductorios que analizaban el periodo (Calvo, 1985). Como indicaba en la introducción del volumen Luis González Seara, comisario general de Europalia-85 España, esta publicación fue concebida como un "gran catálogo panorama del arte español de las últimas décadas" que continuara el esfuerzo de Europalia-85 para difundir la realidad cultural española en el exterior. En la selección de obras para esta exposición se había optado por un arte no político. En el texto de Calvo Serraller, el enfrentamiento entre los dos bandos en materia artística y política se presentaba como cosa del pasado. El rumbo de España estaba orientado más allá del país.

Coincidimos con Jesús Carrillo $(2007,2009)$ cuando analiza cómo las líneas maestras de la narración principal de las prácticas artísticas del franquismo fueron hijas de la transición y marcaron la dirección que seguiría la historiografía después. Una dirección donde la cultura había de presentarse desligada de todo compromiso político y era evaluada según patrones estéticos y de autonomía. Esto dejó fuera del relato a las prácticas conceptuales de contenido crítico de los 1970 (Carrillo, 2007, 2009), pero también afectó al tratamiento dado a las iniciativas artísticas en las que se reconocía un compromiso político que no había desaparecido de la narración. Un buen ejemplo de ello es, como veremos, la historia de los tres grupos de vanguardia surgidos entre los 
años 1950 y 1960 a los que Emma Dent (1995) hace referencia: informalismo, experimentalismo (abstracción geométrica) y realismo social.

\section{El informalismo}

5 Tras la Segunda Guerra Mundial el régimen abandonó la defensa de un arte politizado y franquista para sustituirla por un discurso cuyos valores tenían mucho en común con los del discurso formalista angloamericano, si bien éstos se vieron convenientemente aderezados por los rasgos de españolidad que había de tener toda producción artística del país. La vanguardia abstracta, vaciada de toda carga política, se acabaría convirtiendo en una de las imágenes más populares del franquismo desarrollista. La abstracción informalista, cuyos representantes principales fueron los artistas del grupo El Paso aparecido en 1957, recibió un decidido apoyo oficial y resultó premiada en certámenes internacionales como las bienales de Venecia y Sao Paulo.

6 Frente a la idea de una creación al margen de la política difundida por la dictadura a partir de los años 1950, los organizadores de la exposición española en la Bienal de Venecia de 1976 querían "demostrar que el vanguardismo español [...] [había] sido moldeado [...] por el proceso de una lucha ideológica” (Bozal y Llorens, 1976). Su intención era recuperar para el antifranquismo y, a través de él, para el futuro democrático, el valor simbólico de la vanguardia que la dictadura había monopolizado anteriormente. La posición teórica de carácter combativo y comprometido de la comisión encargada del proyecto se advierte en la misma estructura de la exposición. No en vano, el prefacio de su narración lo constituían el Pabellón de la República Española en la Exposición Internacional de París de 1937 y la obra gráfica republicana de la guerra civil. Toda vanguardia aparecida bajo el franquismo se presentaba como un desafío al régimen puesto que en ella se encontraba un germen de independencia que el régimen no podía tolerar (Bozal, 1976a). De este modo, sin poner en duda la calidad estética de algunas de las corrientes apoyadas por el régimen, se interpretaba la abstracción como desafío a la dictadura. Habría sido el resultado de la inquietud de los artistas y de su resistencia a limitarse al campo de acción impuesto al arte en los años 1940. Su antifranquismo era leído en una clave plástica, es decir, no tenía que ver con los contenidos de las obras sino con el desbordamiento de las restricciones que su lenguaje abstracto implicaba. Su origen no podía encontrarse pues en el marco impuesto por el contexto franquista sino en sus márgenes. De ahí que se negara rotundamente que el informalismo expresara la esencia de la cultura española, que había sido uno de los principales argumentos con los que éste había sido presentado por la dictadura. Es más, los comisarios veían en las obras informalistas una crítica de alcance universal, que se refería a la cultura occidental.

7 El libro Arte del franquismo coordinado por Antonio Bonet (1981) constituía una especie de respuesta a la muestra española de 1976 en Venecia según Julián Díaz Sánchez (1998). El capítulo "De una vanguardia bajo el franquismo" de Juan Manuel Bonet se cerraba mencionando la aparición de los grupos del informalismo, la abstracción geométrica y el realismo social. A partir de entonces, se iniciaba una nueva etapa en la que la "normalización cultural" se había cumplido (Bonet, 1981). La cuestión de la relación con la política del régimen de estas corrientes quedaba así fuera de cuadro. Los movimientos de vanguardia de 1957, informalismo y abstracción geométrica (significativamente, el realismo social no formaba parte del elenco de iniciativas de 
vanguardia), serían tratados sin embargo por otro de los autores de Arte del franquismo, Gabriel Ureña. Éste publicó en 1982 Las vanguardias artísticas en la postguerra española. 1940-1959, un libro que fue criticado por Francisco Calvo Serraller (1985) en su revisión del "medio siglo de vanguardia" por carecer de sentido crítico y perspectiva histórica y abordar "ciertos oportunismos anecdóticos" de los pintores informalistas en relación con el régimen.

Ciertamente el problema del apoyo oficial recibido por los informalistas era una cuestión delicada que se había puesto sobre la mesa con anterioridad. Entre 1959 y 1960 Antoni Tàpies, Antonio Saura y Manuel Millares se desvincularon de la esfera de las exposiciones oficiales. En relación con este hecho la crítica antifranquista empezó a denunciar la instrumentalización de la abstracción informalista por parte del régimen (García, 1959, 1960). También algunas publicaciones se hicieron eco de esta crítica en España como, por ejemplo, la revista Acento Cultural que dedicó su octavo número de 1960 al Equipo 57 para contrarrestar el interés que se habían tomado anteriormente por el informalismo, al que se calificaba de arte apoyado por el régimen. Igualmente, en el extranjero se empezó a considerar el carácter propagandístico que revestía la nueva escuela pictórica española (Edgar, 1960). De la lectura de los artículos se desprende que la crítica se dirigía sobre todo a desenmascarar la estrategia oficial y no contra los artistas. Quizá para disipar las dudas que hubiera respecto a su posicionamiento, en 1961 Millares y Saura expresaron el compromiso y sinceridad de sus propuestas plásticas en Acento Cultural (Millares, 1961; Saura, 1961). A partir de esos años tanto ellos dos como Tàpies participaron en exposiciones antifranquistas al tiempo que su obra se vendía en los circuitos internacionales de arte. Los tres quedaron incluidos en la nómina de expositores en la Bienal de Venecia de 1976 donde, como hemos visto, se explicaba la rebeldía de su propuesta en relación con las directrices del régimen.

Valeriano Bozal explicaba el apoyo oficial que la dictadura había ofrecido a las corrientes artísticas renovadoras se debía a su incapacidad para ofrecer una alternativa ideológica y cultural propia. Por su parte, la colaboración de los intelectuales en la actividad oficial se debía a que la intelectualidad antifranquista no había podido crear mecanismos culturales que fueran autónomos con respecto al poder establecido y que estuvieran ligados a la clase obrera (Bozal, 1976a). En los años 1980, Calvo Serraller (1985) afirmaba que estas cuestiones iban perdiendo interés progresivamente. Este autor hacía hincapié, eso sí, en una interpretación del informalismo en clave crítica con la dictadura. Cabría preguntarse cuánto deben las interpretaciones del informalismo en clave antifranquista de autores como Emma Dent (1995), Ramón Tió Bellido (2005) o Michelle Vergniolle Delalle (2004) a los esfuerzos de los intelectuales antifranquistas, primero, y de los de la democracia, después, por integrarlo en sus discursos. En los años 1990 autores como Julián Díaz Sánchez (1998) trataron en sus investigaciones el proceso por el cual la dictadura hizo del informalismo la estética oficial de finales de los cincuenta y la cuestión del uso interesado que hizo la dictadura de la abstracción ha pasado a formar parte del relato historiográfico. No es frecuente encontrar referencias a la otra cara de la moneda, si bien es cierto que el problema de la responsabilidad que tuvieron los artistas en su participación en las muestras oficiales ha sido abordado recientemente por Jorge Luis Marzo (2006) que ha hablado de una vanguardia colaboracionista. 


\section{La abstracción geométrica}

10 Según los organizadores de España, vanguardia artística y realidad social, el Equipo 57 era el mejor representante de la corriente de la abstracción geométrica desarrollada por una serie de artistas y de grupos a finales de los años 1950. El crítico Vicente Aguilera Cerni había tratado de aglutinar, sin éxito, a todos estos creadores bajo el nombre de "arte normativo". Los organizadores de la muestra veneciana de 1976 destacaban que el Equipo 57 habría sido el primer grupo de vanguardia español en posicionarse frente al régimen planteándose una problemática que tenía que ver con cuestiones éticas. Ya en 1966, el propio Bozal había señalado que lo más interesante de la iniciativa normativa era su producción teórica y que sus obras no podían responder a ella. El motivo era que la influencia del arte experimental sobre su medio sólo podía tener lugar a través del diseño pero en un país económicamente subdesarrollado como era España, con un diseño industrial balbuciente, las corrientes experimentales se quedaban en meros objetos de galería (Bozal, 1966a). La orientación marxista de este autor era palpable en sus análisis, y también se encuentra en los textos de las publicaciones que rodearon a la exposición española en la Bienal de Venecia. En 1976 Bozal volvía a reiterar que el problema de esta iniciativa había sido que las cuestiones éticas que constituían la preocupación principal del Equipo 57 se habían pretendido resolver únicamente mediante la investigación plástica (Bozal, 1976a). Por este motivo, muchos artistas normativos habrían empezado a trabajar en una estética realista que, en consonancia con los movimientos de protesta del momento y con otras iniciativas culturales, sí les permitía dar respuesta a sus inquietudes éticas, sociales y políticas (Bozal, 1966a, 1966b).

11 El decidido posicionamiento político de los artistas del Equipo 57 no se mencionaría a la hora de abordar su producción dentro de la vanguardia española de postguerra (Ureña, 1982). En cambio, el valor formal de su trabajo plástico y el interés teórico de su producción eran juzgados muy positivamente por este autor. De hecho, para él esta iniciativa revestía un interés mayor en comparación con el pragmatismo, la pobreza teórica y la particularidad de intereses de El Paso (Ureña, 1982). El Equipo 57 y el arte normativo en general serían el objeto de la investigación de Ángel Llorente en su tesina de 1982 que tardaría décadas en publicarse (2003). Además de reconstruir la trayectoria del Equipo 57, este trabajo reproducía muchos de sus escritos y analizaba su contenido en detalle, prestando singular atención a las investigaciones teóricas sobre el arte y a su materialización plástica. La idea de la coherencia con un compromiso social que explicaba el abandono de la abstracción (fuera ésta geométrica o informalista) por el realismo fue publicada ya por Valeriano Bozal a mediados de los años 1960 (Bozal, 1966b). Sin embargo, mientras que este autor no veía en ello ningún tipo de claudicación sino el efecto de un movimiento lógico y coherente, no serà ésta una opinión compartida por todos. Críticos de izquierdas como Vicente Aguilera Cerni habían realizado también un análisis muy similar al de Bozal en relación con los motivos por los que los artistas de la abstracción geométrica habían abandonado sus investigaciones "normativas" para dedicarse al realismo (Aguilera, 1970). Sin embargo, Aguilera Cerni advertía que los caminos por los que continuó el tránsito de los normativos sólo se podían explicar por la situación de la cultura artística española en el momento. El realismo social habría aparecido como un "remedio de urgencia" (Aguilera, 1970). 
12 El monopolio del régimen franquista en relación con las claves interpretativas del informalismo en un tono afín al discurso oficial había sido socavado en cierto sentido cuando obras como las de Saura, Millares o Tàpies se mostraron en las exposiciones organizadas por las iniciativas antifranquistas. La idea de que su lenguaje plástico se rebelaba contra las imposiciones del régimen, que era expuesta, por ejemplo, en la Bienal de Venecia de 1976, habría de ser interpretada en esta misma línea de reivindicar su compromiso antifranquista. Podría decirse que la puesta en valor del trabajo del Equipo 57 ha requerido, en cierto sentido, el proceso contrario: atenuar sus vínculos con la política antifranquista, especialmente con todo aquello vinculado con el comunismo del que eran militantes tres de los más activos representantes del "normativismo", Agustín Ibarrola, José Duarte y Antonio Pericás. Aunque se haga referencia a la militancia de estos intelectuales en el partido comunista no se suele analizar la producción del Equipo 57 en relación con estas ideas. La atención se concentra sobre una investigación formal y plástica, que presentaba ciertos toques sociales cuyos referentes no se aclaran. Calvo Serraller citaba a José María Moreno Galván para referirse al compromiso social de las investigaciones formales de la abstracción geométrica. Presentada como reacción al subjetivismo romántico del informalismo, la objetividad del Equipo 57 (así como de los demás grupos de artistas comprometidos del momento) habría puesto las bases para que surgieran una serie de métodos de creación plástica "en frío" como eran el distanciamiento y el desdoblamiento, que el autor valoraba positivamente por el empleo que harían de ellos iniciativas artísticas posteriores (Calvo, 1985).

13 Al mismo tiempo y en consonancia con la preferencia por el juicio estético más tradicional, es frecuente encontrar términos que descalifican, en un plano plástico, su abandono de la abstracción geométrica a favor del realismo. La idea de que se trató de una caída, de una regresión, de un paso atrás en un camino de progreso es recurrente en la historiografía. Tal y como veremos, las críticas están en consonancia con las que recibiría el realismo social. Permanecer fieles a las ideas, y proceder por ello a una especie de suicidio estético después de hacer un arte de vanguardia en un sentido formalista puede ser heroico y hasta puede servir para dar relieve al valor de dicho arte de vanguardia, pero no es suficiente para evitar los juicios negativos sobre el punto de destino. El peso que han ido adquiriendo los esquemas formalistas y sus juicios estéticos quizá tenga algo que ver en esto. Es posible que, como resultado de estos criterios de evaluación, los juicios negativos sobre el realismo sean necesarios para hacer posible una evaluación radicalmente positiva de la abstracción geométrica.

Situar la abstracción geométrica en el origen de las tendencias realistas como había hecho Bozal (1966a) no calará de un modo relevante en la historiografía de las décadas posteriores. En la mayoría de los relatos se ha reforzado la imagen de un grupo de experimentación plástica con lazos hacia las primeras vanguardias, hacia movimientos internacionales tanto del pasado, como contemporáneos, precedente de iniciativas que se desarrollarían en un futuro (arte óptico, cinético, concreto, arte vinculado a las tecnologías, etc.). Lo que Valeriano Bozal había calificado en los años 1960 y 1970 como errores cometidos por el Equipo 57 al analizar la situación y diseñar sus estrategias de actuación, se ha colocado bajo una luz que, con el tiempo, ha ido virando hasta ser distinta. La abstracción geométrica y su mejor representante, el Equipo 57, habría sucumbido "a un principio complejo de realidad", convirtiéndose en "una senda, casi perdida, de nuestra vanguardia" (Marchán, 1993). En definitiva, se había tratado de 
unos adelantados a su tiempo, de unos incomprendidos que habían sufrido "la indiferencia e inoperancia del público" (Bonet, 1995). La España del momento no estaba preparada para la abstracción geométrica.

\section{El realismo social}

Estampa Popular fue la respuesta plástica a la aparición de un frente realista contra la dictadura en otros campos de la cultura. Así lo indicaba Valeriano Bozal (1976a) que consideraba que los artistas habían hecho lo correcto al encauzar su compromiso social en el realismo; según hemos observado en el caso del Equipo 57. De hecho, como ya hemos explicado con anterioridad (De Haro, 2010), varios de los miembros de la comisión encargada de organizar la exposición de 1976 habían estado implicados en este frente plástico realista desde sus inicios puesto que habían formado parte de la red de artistas e intelectuales de Estampa Popular. Agustín Ibarrola había estado integrado en Estampa Popular de Vizcaya, Alberto Corazón había colaborado con Estampa Popular Galega y los miembros del Equipo Crónica habían formado parte de Estampa Popular de Valencia. Eduardo Arroyo tenía relación con el núcleo de intelectuales vinculados a Valencia. Por su parte, Valeriano Bozal y Tomás Llorens habían estado implicados en el desarrollo de Estampa Popular de Valencia y del Equipo Crónica.

Valeriano Bozal opinaba que si bien la intención con la que había surgido Estampa Popular era positiva y había planteado los problemas de un modo acertado, al igual que el Equipo 57, Estampa Popular había cometido errores. Fundamentalmente el de no renunciar a hacer "arte" y el del "populismo" (Bozal, 1976a). La aparición de Estampa Popular de Valencia en 1964 habría venido a solucionar este problema, puesto que su trabajo respondía más adecuadamente a estas cuestiones como resultado de un mejor análisis de la situación social y cultural. El Equipo Crónica, formado por tres de los artistas de la agrupación valenciana de Estampa Popular, también era el fruto de este análisis de los problemas sociales. La diferenciación radical de los artistas valencianos con respecto a todos los demás grupos de Estampa Popular era, por otra parte, una idea que ya habían publicado tanto Valeriano Bozal como Tomás Llorens antes de 1976. Por ejemplo, el primero se había referido a la crisis y las limitaciones de Estampa Popular en su estudio del realismo posterior a la Guerra Civil (Bozal, 1966a), y el segundo había indicado expresamente las diferencias que él advertía entre el núcleo valenciano de Estampa Popular y todos los demás en 1965 (Llorens, 1965). En investigaciones anteriores hemos analizado la representación de Estampa Popular en la Bienal de Venecia y hasta qué punto estaba justificado contraponer los grupos valencianos a todos los demás de Estampa Popular. También hemos señalado cómo la idea de que Estampa Popular era cosa del pasado parecía algo generalizado en 1976 con lo que la impresión de cese de actividad podía estar justificada (De Haro, 2010). Quizá por este motivo en 1976 y 1978 se presentaron las primeras memorias de licenciatura sobre los grupos madrileño (Rodríguez, 1976) y sevillano de Estampa Popular (Marqués, 1978).

En julio de 1977 se celebró en Santander el curso de arte de la Universidad Internacional Menéndez Pelayo La Vanguardia artística: Mito y Realidad. Allí tuvieron lugar una serie de debates entre especialistas en el que se definieron los dos bandos a los que nos hemos referido al principio de este texto. La polémica entre ambos acerca de la vanguardia así como al camino que ésta había de seguir en un futuro continuó en los catálogos de las exposiciones así como en la prensa. Por parte de los segundos se 
criticaba la falta de futuro y de interés del compromiso político que representaban tanto el arte conceptual como el realismo crítico del Equipo Crónica, por parte de los primeros se denunciaba lo poco trabado del discurso teórico y la errada selección de artistas que hacían estos jóvenes historiadores y críticos. Como muestra de todo ello, citemos tan sólo algunos ejemplos como los catálogos de 1980 (Bonet, 1979a), artículos como el de Bonet en Pueblo (1979 b), los aparecidos en Batik, tanto a favor como en contra de la muestra (Llorens, 1979; Rubio, 1979) o el titulado "Contra el arte de los sesenta" (Bonet, 1983).

Como ya hemos indicado no hubo vencedores en esta contienda. En cambio sí hubo grandes perdedores, y entre ellos se encontraba Estampa Popular. Su evidente antifranquismo les valió una consideración positiva, pero su trabajo fue considerado de poca calidad estética. Así Antonio Gállego hablaba de que Estampa Popular había sido un chorro de aire fresco en su época, si bien había fracasado por "la persecución oficial y [...] por la maldad intrínseca de muchas de las obras" (Gállego, 1979). En España: veinte años de arte de vanguardia la cronología de sus actividades se señalaba en la sección correspondiente del texto, pero ninguna obra de Estampa Popular se reproducía junto al texto de análisis que iba ilustrado con imágenes en color, allí se le dedicaban sólo unas líneas (Calvo, 1985). Es cierto que tampoco se dedicaba mucho más a iniciativas como las del Equipo Crónica, que se vinculaban al arte pop. De todas estas propuestas lo que destacaba a ojos del autor era su contribución plástica, ya que habían contribuido a la incorporación de los métodos de enfriamiento y distanciamiento crítico en la ejecución lo cual sería un elemento fundamental en el trabajo de artistas jóvenes del momento (Calvo, 1985). En definitiva, las cuestiones plásticas, estéticas y formales se señalaban como la medida para el arte político.

Vistas bajo una luz diferente y cortadas con el patrón de una historia del arte preocupada por el progreso estético - entendido en el sentido del modernismo angloamericano - algunas de las ideas que Valeriano Bozal y Tomás Llorens habían señalado con anterioridad tuvieron un peso definitivo sobre la fortuna historiográfica de Estampa Popular. La idea de que Estampa Popular de Valencia y el Equipo Crónica heredaban y mejoraban el espíritu de Estampa Popular (que había errado en sus planteamientos) es la más evidente de ellas (De Haro, 2010). El rechazo de críticos como Juan Manuel Bonet hacia el Equipo Crónica no han tenido un gran eco historiográfico (la posición de Bonet en relación con el arte de los 1960 parece haber cambiado); sin embargo, sí lo ha tenido la defensa de una valoración estética y plástica del arte. Así las aportaciones del Equipo Crónica se equipararon al pop y rara vez se han emitido juicios acerca de si su trabajo combatió mejor o peor al franquismo. En cambio, es un lugar común hablar de ello en relación con Estampa Popular, como lo es referirse a su dependencia o no del partido comunista. A diferencia de lo sucedido con el Equipo 57 (o con el Equipo Crónica) donde el tema se elude o se trata con discreción, en el caso de Estampa Popular la cuestión del comunismo es problematizada constantemente. Quizá su identificación como realistas haya favorecido cierta asociación con el realismo socialista, una estética considerada tradicionalmente como retrógrada por la historia del arte. En todo caso las acusaciones de ser panfletarios, anecdóticos, retrógrados o fracasados no son infrecuentes. Éstas a veces se presentan de un modo positivo al hablar del carácter utópico, romántico, quimérico de sus pretensiones. Así se indicaba, por ejemplo, en la primera gran exposición retrospectiva sobre Estampa Popular celebrada 
en 1996 en el IVAM, dirigido entonces precisamente por Juan Manuel Bonet (Gandía, 1996).

\section{Salto al presente}

Para Valeriano Bozal la "crisis de la vanguardia" era una crisis productiva; a su modo de ver, dicha crisis suponía la apertura de nuevas expectativas (Bozal, 1976a). A tenor de lo que este autor indicaba en sus textos, la exposición de 1976 no trataba de ofrecer sólo un relato sobre el desarrollo de la vanguardia durante el franquismo, sino que mostraba las líneas que la vanguardia podía seguir en el futuro. Tras la crisis, las actividades relacionadas con el arte podían orientarse en tres sentidos que se enmarcaban dentro del "realismo": problematizando el lenguaje artístico, la función del arte y el papel del artista, problematizando la condición de obra de arte y de actividad artística o replanteando la condición profesional del artista. Formando parte de estas líneas el autor se refería a Eduardo Arroyo, Agustín Ibarrola, Equipo Crónica, propuestas conceptuales como las del Grup de Treball, el trabajo de Alberto Corazón o iniciativas como la Asociación de Artistas Plásticos de Madrid (Bozal, 1976b). Si la historiografía ha hecho de España, vanguardia artística y realidad social el punto final del arte del franquismo, sus comisarios no la pensaron de ese modo y tampoco la vieron de este modo otros especialistas del momento. Muchos de ellos han ido cambiando su posición, adaptándose y aceptando el modelo historiográfico (tradicional) que se ha ido fraguando al calor de la transición. Como ha indicado Jesusa Vega, la transformación de la historia del arte y de su enseñanza que vino de la mano de los planteamientos de lo que se ha denominado "new art history" no se produjo en España (Vega, 2009). Quizá el "mono del desencanto" del que ha hablado Teresa Vilarós (1998) también se podría rastrear en la historia del arte español del franquismo.

En la actualidad el trabajo de muchos investigadores está empezando a cambiar el panorama del relato existente sobre la historia del arte del franquismo. El proyecto de Desacuerdos, nacido en 2003 con la intención de poner en cuestión el relato hegemónico y que dio lugara una investigación que releía en clave política la historia reciente del arte español, es un buen ejemplo de ello. Los cambios en la exposición permanente del Museo Nacional Centro de Arte Reina Sofía (en los cuales están implicados muchos de los integrantes del proyecto Desacuerdos) también constituyen propuestas en este sentido. En concreto, la sección del museo titulada ¿La guerra ha terminado? Arte en un mundo dividido (1945-1968) se ocupa precisamente de las iniciativas artísticas que nos han guiado a lo largo de este texto, planteando una historia de estratos superpuestos que abre el discurso, las obras y los nombres conocidos a un diálogo más allá del canon (que ha incluido, por ejemplo, a Estampa Popular). La introducción de la publicación asociada a la exposición es explícita en las intenciones e hipótesis de trabajo críticas con el discurso heredado con las que se llevó a cabo esta tarea (Carrillo, Peiró, 2010). Quizá no haya que esperar tanto para que proliferen los análisis de la pintura y la escultura de los años 1950 y 1960 hechos desde el punto de vista de los estudios culturales. 


\section{BIBLIOGRAFÍA}

AA.VV., Acento Cultural, 1960, $\mathrm{n}^{\circ} 8$.

AGUILERA CERNI Vicente, Iniciación al arte español de la postguerra, Barcelona, Península, 1970.

BONET Antonio, “En torno al año 1957”, en J. Gállego, V. Bozal, A. Bonet y S. Marchán, Arte en España 1918-1994 en la colección Arte Contemporáneo, Madrid, Alianza, 1995, p. 31-41.

BONET CoRrea Antonio (coord.), Arte del franquismo, Madrid, Cátedra, 1981.

BONET Juan Manuel, 1980, Madrid, Juana Mordó, 1979a.

-, "Después de la batalla", Pueblo, $1979 b$.

-, "Contra el arte de los sesenta", Comercial de la pintura, 1983, nº 1, p. 3-9.

BOZAL Valeriano, El realismo entre del desarrollo y el subdesarrollo, Madrid, Ciencia Nueva, 1966 .

-, “Constructivismo y realismo", Artes, 1966b, nº 74, p. 7-12.

-, "La imagen de la posguerra”, en V. Bozal y T. Llorens (coord.), España. Vanguardia artística y realidad social: 1936-1976, Barcelona, Gustavo Gili, 1976a, p. 83-110.

-, "Para hablar de realismo no hay que hablar de realismo", en V. Bozal y T. Llorens (coord.), España. Vanguardia artística y realidad social: 1936-1976, Barcelona, Gustavo Gili, 1976b, p. 111-135.

BozAL Valeriano y LLORENS Tomás, “Introducción”, en V. Bozal y T. Llorens (coord.), España. Vanguardia artística y realidad social: 1936-1976, Barcelona, Gustavo Gili, 1976, p. XI-XX.

CALVO SERRALlER Francisco (coord.), España: medio siglo de arte de vanguardia 1939-1985, Madrid, Fundación Santillana, Ministerio de Cultura, 1985.

CARRILlo Jesús, “Amnesia y Desacuerdos. Notas acerca de los lugares de la memoria de las prácticas artístico-críticas del tardofranquismo”, Arte y políticas de identidad, vol. 1, 2009, p. 1-22.

-, "Conceptual Art Historiography in Spain", 2007. En línea <www.vividradicalmemory.org/ htm/.../carrillo.pdf> [consultado 10/09/2011].

CARRILlo Jesús y PeIRó Rosario, “Introducción”, en S. Espinós y R. Gallego (coord.), ¿La guerra ha terminado? Arte en un mundo dividido (1945-1968)?, Madrid, MNCARS, 2010, p. 13-27.

DE HARO GARCíA Noemi, Grabadores contra el franquismo, Madrid, CSIC, 2010.

DENT COAD Emma, "Painting and Sculpture: The Rejection of High Art", en H. Graham y J. Labanyi (eds.), Spanish Cultural Studies. An Introduction, Oxford, Oxford University Press, 1995, p. 299-304.

DíAZ SÁNCHEZ Julián, La “oficialización" de la vanguardia artística en la postguerra española: el informalismo en la crítica de arte y los grandes relatos, tesis doctoral, Universidad de Castilla la Mancha, 1998.

EDGAR Natalie, “Is There a new Spanish School?", Art News, vol. 59, n 5, 1960. Citada por G. Tusell, "La internacionalización del arte abstracto español: el intercambio de exposiciones con los Estados Unidos (1950-1964), Espacio, Tiempo y Forma, t. 16, 2003, p. 223-232.

GÁLLEGo Julián, Historia del grabado en España, Madrid, Cátedra, 1979.

Gandía Casimiro José (comis.), Estampa Popular, Valencia, IVAM, 1996.

GARCíA Pascual, “A propósito de la crítica de una crítica”, Nuestras Ideas, nº 8, 1960, p. 45-47. 
-, “A propósito de una exposición”, Nuestras Ideas, nº 7, 1959, p. 108-111.

GRAHAM Helen y LABANYI Jo (eds.), Spanish Cultural Studies. An Introduction, Oxford, Oxford University Press, 1995.

LloRens Tomás, "El espejo de Petronio”, Batik, n 52, 1979, p. 6-8.

-, “Un any d'Estampa Popular de València", Serra d'Or, nº 11, 1965, p. 41-43.

LLORENTE Ángel, Equipo 57, Córdoba, Fundación Rafael Botí, 2003.

LÓPEZ CUENCA Alberto, "El traje del emperador. La mercantilización del arte en la España de los 80", Revista de Occidente, $\mathrm{n}^{\circ}$ 273, 2004, p. 21-36.

MARCHÁN FIz Simón, “El Equipo 57, una senda casi perdida en nuestra vanguardia”, en M. González y B. Díaz (coord.), Equipo 57, Madrid, MNCARS, 1993, p. 49-64.

MARQUÉS FERRER Virginia, Estampa Popular: el Grupo Sevilla, memoria de licenciatura, Universidad de Sevilla, 1978.

MARZo Jorge Luis, Arte moderno y franquismo. Los orígenes conservadores de la vanguardia y de la política artística en España, 2006. En línea <http://www.soymenos.net/arte_franquismo.pdf> [consultado 07/08/2011].

Millares Manuel, “Destrucción-construcción en mi pintura", Acento Cultural, $\mathrm{n}^{\text {os }} 12-13$

(extraordinario), 1961, p. 75.

RODRÍGUEZ VeLA Ma Paz Cristina, Aproximación a la pintura realista de la postguerra: la Estampa Popular, memoria de licenciatura, Universidad Complutense de Madrid, 1976.

RUBIO NAVARRo Javier, “1980. El sentido de la marcha”, Batik, n 52, 1979, p. 9-10.

SAURA Antonio, "Carta abierta", Acento Cultural, nos 12-13 (extraordinario), 1961, p. 76-79.

TIó BELLIDo Ramón, L'art et les expositions en Espagne pendant le franquisme, París, Isthme Éditions, 2005.

UREÑA Gabriel, Las vanguardias artísticas en la postguerra española. 1940-1959, Madrid, Istmo, 1982.

VeGA Jesusa, 2009, “Points de repère pour l'histoire de l'art”, Perspective, nº 2, p. 180-198.

Vergniolle-Delalle Michelle, Peinture et opposition sous le franquisme. La parole en silence, París, L'Harmattan, 2004.

VILARós Teresa, El mono del desencanto. Una crítica cultural de la transición española (1973-1993), Madrid, Siglo Veintiuno, 1998.

\section{RESÚMENES}

El relato dominante elaborado desde la disciplina de la historia del arte español de la segunda mitad del siglo XX lo presenta avanzando por una línea de progreso e innovación hacia la autonomía. Las líneas maestras de este relato quedaron definidas principalmente por diversas publicaciones aparecidas en las décadas de los setenta y los ochenta. A lo largo de la transición se fue verificando un proceso por el cual las cuestiones estéticas pasaron a ocupar un primer plano en la historia del arte española. Aquí nos ocuparemos de ver cómo esto ha afectado al tratamiento historiográfico de las corrientes que se han relacionado con el compromiso antifranquista (informalismo, abstracción geométrica y realismo social). 
The dominant narrative in the Spanish art history of the second half of the 20th century has presented the progress of Spanish art and its innovation in its way towards autonomy. The master lines of this discourse were defined by several publications of the decades of the seventies and eighties. During the transition to democracy a process took place where aesthetic matters became the main question in Spanish art history. Here we will see how this has affected the treatment historiography has given to the initiatives linked to antifrancoist engagement (informalism, abstract geometry and social realism).

\section{ÍNDICE}

Palabras claves: arte español, siglo XX, antifranquismo, arte comprometido, arte de vanguardia Keywords: Spanish art, twentieth century, anti-Franco, engaged art, modern art

\section{AUTOR}

\section{NOEMI DE HARO GARCÍA}

Universidad Autónoma de Madrid 